\title{
OS BRANCOS TORMENTOS DA LEITURA
}

OS BRANCOS tormentos do testemunho. Comunicação por Georges Didi-Huberman. Tradução de Renata Correia Botelho e Rui Pires Cabral. Lisboa: Culturgest. 15 mar. 2012. 1 vídeo (46 min). Disponível em: https://proymago.pt/didi-video. Acesso em: 19 abr. 2021.

Em 2012, por ocasião do lançamento da tradução portuguesa do seu livro Images malgré tout, Georges Didi-Huberman fez uma palestra sobre o tema abordado no livro - a representação do holocausto - , a partir da proposição de uma leitura para a instalação Entre a escuta e a palavra: Últimos testemunhos, Auschwitz-Birkenau, 1945-2005, da artista Esther Shalev Gerz. Como ouvimos no início do seu trabalho:

\footnotetext{
Bom, eu procurei um tema que estivesse relacionado com o livro que hoje sai, mas, na verdade, não queria retomar o tema já tratado em Imagens apesar de tudo. Vou antes falar-vos de uma obra de arte. Trata-se de uma instalação recente, de 2005, realizada por Esther Shalev-Gerz, uma artista lituana, israelita, franco-sueca...É um dispositivo absolutamente notável que se intitula Entre a escuta e a palavra: Últimos testemunhos, Auschwitz-Birkenau, 1945-2005. Este dispositivo foi apresentado num amplo espaço da Câmara Municipal de Paris, em 2005, no quadro das comemoraçōes da libertação do campo de Auschwitz (DIDI-HUBERMAN, 2012, 00:26-00:43).
}

A partir de sua relação com a instalação de Esther Shalev-Gerz, DidiHuberman nos oferece uma leitura da obra e uma belíssima reflexão sobre a experiência de leitura. Como não é possível, nesta resenha, tratar dos múltiplos aspectos da palestra, gostaria de apresentá-la a partir da minha relação com ela e chamar a atenção para o modo como Didi-Huberman constrói a leitura.

A fala do autor, permeada por imagens que são projetadas ao público, possui em torno de 45 minutos. E não é difícil perceber que ela está 
estruturada em três partes (em torno de 15 minutos para cada parte): 1) Apresentação da instalação Entre a escuta e a palavra: Últimos testemunhos, Auschwitz-Birkenau, 1945-2005, de Esther Shalev-Gerz, a partir da imagem dos "brancos"; 2) Uma memória "dos brancos" ligada à representação; e 3) Uma reflexão teórica sobre a representação a partir da imagem dos "brancos". Náo parece nada, mas essa estrutura coloca em funcionamento um modo de ler que nos interpela neste presente e sobre a qual discutiremos no final desta resenha. Essa estrutura é a mesma que Didi-Huberman tem usado em outros trabalhos e é a que vemos em autores como Walter Benjamin e João Cezar de Castro Rocha (para citar um leitor do presente). Vejamos como cada seção se constitui.

A primeira parte é impressionante (e comum ao mesmo tempo) porque Didi-Huberman começa a falar da instalação a partir da sua relação com ela e, conforme a descreve, vamos "vendo" a obra surgir diante de nós. Assim, descobrimos que a instalação nasceu de um convite da Câmara Municipal de Paris para Esther Shalev Gerz fazer uma obra que comemorasse os 60 anos da libertaçáo do campo de Auschwitz. E, conforme escutamos a descrição feita por Didi-Huberman, lembramos o início de outro livro seu, em que ele nos diz que diante de uma imagem " [...] podemos mesmo experimentar certo gozo em nos sentirmos alternadamente cativos e liberados nessa trama de saber e de não-saber, de universal e de singular, de coisas que pedem uma denominação e coisas que nos deixam de boca aberta...” (DIDIHUBERMAN, 2013, p. 9).

Essa "trama de saber e de não-saber, de universal e de singular" e "de coisas que pedem uma denominação e coisas que nos deixam de boca aberta [...]" parece apontar para algo muito importante: o que vemos nesta primeira parte de sua palestra é um ponto de partida da leitura, e o ponto de partida parece ser a relação, isto é, o sentido parece nascer da relação entre Didi-Huberman e a obra da Esther Shalev-Gerz. Aqui podemos lembrar de Daniel Link, que define a leitura como "[...] a correlação de duas séries de sentido, uma inerente ao objeto e outra inerente ao sujeito" (LINK, 2002, p. 19), ou como propóe o próprio Didi-Huberman na belíssima leitura que faz do texto "Montanha abaixo", de Walter Benjamin:

Esse texto de Benjamin descreve nada mais do que a montagem da experiência enquanto tal. Primeiro, há a queda do corpo: elemento sintomal de toda experiência em que o sujeito, levado por uma corrida literalmente "catastrófica" - figurada nesse trecho pela descida da montanha, o entulho das pedras, o peso do corpo, o passo intermitente, o cansaço físico próximo 
do desabamento -, torna-se o brinquedo de seu próprio movimento. Em seguida, há o surgimento das imagens, elas também intermitentes, fulgurantes, renovadas a cada passo, como um jogo [jeu] psíquico com a própria queda. Há, enfim, a constituição de um saber - até mesmo de uma sabedoria - disso tudo: como o alcance [enjeu] do movimento de queda e do fogo de imagens reunidos (DIDI-HUBERMAN, 2015, p. 162-3).

E o saber que nasce da relação com a obra de Esther Shalev-Gerz nos coloca dentro da instalação. É impressionante como, mesmo não conhecendo a obra da autora, nos sentimos passando por ela (e capazes de falar dela) ao assistirmos à descrição feita por Didi-Huberman e às imagens projetadas com fotos e vídeos da instalação. Assim, descobrimos que a obra é composta por 60 testemunhos de 60 sobreviventes do holocausto, com duraçôes variáveis, disponibilizados em 60 notebooks, os quais estão posicionados em mesas que possuem entradas para os visitantes, simulando uma conversa face a face entre o espectador e o testemunho. Além disso, nos diz o autor, a artista separou e montou todos os momentos em que os sobreviventes param de falar, afetados pelo "branco", e os exibiu em três telóes localizados na parte superior da Câmara Municipal de Paris.

Como diz o autor:

Silêncios mostrados mas também, portanto, silêncios montados. De tal forma que se constituiu o que eu chamaria uma espécie de atlas dos brancos...um atlas dos silêncios. Donde, por fim, se desprende algo como o verdadeiro gestus, mas é um gestus implícito, se me é permitido dizê-lo, dos testemunhos enquanto tal (DIDI-HUBERMAN, 2012,12;38-13:08).

Essa primeira parte é belíssima, pois, ao mesmo tempo que apresenta a instalação de Esther Shalev-Gerz, nos propóe uma imagem - os "brancos" - para lê-la. Em Diante da imagem, Didi-Huberman faz uma reflexão sobre a leitura de imagens e sugere que o ponto de partida de nossa relação com as obras é sempre um trecho e não um detalhe. Para o autor, é no trecho que encontramos o sintoma, o saber (para lembrarmos do texto sobre Walter Benjamin) ou o vaga-lume, termos que podemos utilizar para nomear o que nasce de nossa relação com as imagens ou também poderíamos pensar aqui na noçáo de metáfora, tal como proposta por Michel Pêcheux.

Antes de partir para a segunda parte, talvez caberia ressaltar que é o trecho, ou seja, a montagem dos silêncios, que sustenta todos os gestos de leitura de Didi-Huberman em sua palestra. A apresentação de DidiHuberman é construída para chegarmos neste trecho da obra, da montagem 
de silêncios, ou melhor, da montagem de brancos.

O início da segunda parte é impactante (e singelo ao mesmo tempo): "Pouco importa, passemos à frente... Gostaria de vos dizer rapidamente em que é que esta obra me fez pensar inicialmente. Imaginei, perante aquela montagem de silêncios..." (DIDI-HUBERMAN, 2012, 13:41-13:53). Aqui Didi-Huberman fornece uma memória para a imagem dos "brancos" na obra de Esther Shalev-Gerz e a aproxima de uma parábola hassídica sobre o esquecimento e de uma cena de Shoah, o filme de Claude Lanzmann, mais especificamente da sequência de Abraham Bomba em que há a presença dos brancos no seu testemunho.

Assim, para colocar em cena aquilo que lembra ao ver a obra de Esther Shalev-Gerz, Didi-Huberman constrói uma espécie de atlas. A memória aqui aparece como uma montagem daquilo que o palestrante lembrou na sua relação com a instalação. Nesse sentido, também nós, espectadores de Didi-Huberman, lembramos dos autores com os quais ele parece dialogar na construção de suas leituras, justamente na direção da leitura como atlas, como Aby Warburg e Walter Benjamin. Aqui podemos lembrar ainda como, em um poema da Marília Garcia (Parque das ruínas), a leitura aparece como atlas temporário. Ou das reflexôes sobre memória, por Michel Pêcheux.

A questáo é que essa parte é decisiva para o trabalho e também para pensarmos como lemos. É possível imaginar que lemos lembrando e é assim que atribuímos uma história para as imagens que nascem das nossas relaçóes com os textos.

A terceira parte parece, entáo, uma reflexão teórica sobre a representação a partir da imagem dos "brancos". Vejamos como inicia esta parte:

Voltando à obra de Esther Shalev-Gerz, que está, claro, absolutamente ligada a esta problemática, poderíamos fazer duas referências suplementares... Procuro fornecer-vos uma rede de referências possíveis... São referências filosóficas, que podem ser encontradas, em França, em dois filósofos que refletiram sobre a questão da irrepresentabilidade (DIDI-HUBERMAN, 2012, 27:57-28:27).

E, a partir desse ponto, o autor discute com Jean-Luc Nancy e Jacques Rancière, e depois com Roland Barthes, sobre a questão da representação do holocausto, questionando a noçáo de irrepresentabilidade proposta pelos dois primeiros autores. E assim, aos poucos, se aproxima da ideia do título Os brancos tormentos do testemunho - ao analisar como cada palavra que 
o compóe ajuda a refletir sobre as possibilidades de pensar a imagem. Como ele diz em "Inquietar-se diante de cada imagem":

Eu trabalho somente com singularidades (não tenho nada de geral a dizer sobre "a arte", "a beleza” etc.) na medida em que as singularidades têm essa potência teórica de modificar nossas ideias preconcebidas, portanto, de solicitar o pensamento de uma maneira não axiomática: de uma maneira heurística (DIDI-HUBERMAN, 2011, p. 4).

Esse movimento de leitura é fundamental porque a teoria não é ponto de partida (nem a história), mas é mobilizada pela imagem dos "brancos". Aqui temos um sentido de teoria próximo do que vemos em João Cezar de Castro Rocha:

[...] proponho que se recupere o sentido originário da palavra teoria, através do retorno à origem grega. O verbo theorein quer dizer "olhar para", "contemplar", "pesquisar", o que supóe um objeto a ser contemplado e pesquisado - e a tautologia é indispensável, pois esclarece o caráter transitivo da atividade teórica na cultura clássica. A theoria somente se articula no enfrentamento com um objeto determinado (ROCHA, 2008, p. 67).

Ou como vemos nos textos do próprio Didi-Huberman (2011), especialmente em "Inquietar-se diante de cada imagem", em que ele considera a teoria é mobilizada a partir da relaçáo que o espectador estabelece com a imagem. Reflexão parecida sobre a teoria vemos no belíssimo e provocativo texto "Reflexôes críticas: na cama com Madonna", de Thierry de Duve.

Nesse sentido, a palestra de Georges Didi-Huberman nos apresenta uma prática de leitura e, ao mesmo tempo, uma teoria sobre a leitura. Os brancos tormentos são dos testemunhos, mas também são da leitura. Diferentemente dos "pontos vazios" que Iser propóe em relação a um texto literário, podemos pensar que os brancos estão mais próximos ao que Barthes (1987) propóe em "Escrever a leitura": "Nunca vos aconteceu, ao ler um livro, interromper constantemente a vossa leitura, não por desinteresse, mas, pelo contrário, por afluxo de ideias, de excitaçôes, de associaçóes? Numa palavra, náo vos aconteceu ler levantando a cabeça?" (BARTHES, 1987, p. 27). Como os brancos na obra de Eshter Shalev-Gerz, "ler levantando a cabeça" parece um modo de fazer relação entre o vivido e o narrado; na leitura, pode ser o momento em que, da relaçáo entre texto e leitor, nasce um saber, uma imagem ou uma possibilidade de sentido. 


\section{Referências}

BARTHES, Roland. O rumor da língua. Lisboa: Edições 70, 1987.

LINK, Daniel. Como se lê e outras intervençóes críticas. Chapecó: Argos, 2002.

DIDI-HUBERMAN, Georges. Diante do tempo. Belo Horizonte: Editora da UFMG, 2015.

DIDI-HUBERMAN, Georges. Diante da imagem. São Paulo: 34, 2013.

DIDI-HUBERMAN, Georges. Imagens apesar de tudo. Lisboa: KKYM, 2012.

DIDI-HUBERMAN, Georges. Sobrevivência dos vaga-lumes. Belo Horizonte: Editora da UFMG, 2011.

DIDI-HUBERMAN, Georges. Inquietar-se diante de cada imagem. Entrevista realizada por Mathieu Potte-Bonneville e Pierre Zaoui. Trduação de Vinícius Nicastro Honesko. Flanagens, 2011. Disponível em: http://flanagens.blogspot.com/2011/05/inquietar-se-diante-de-cada-imagem.html. Acesso em: 19 abr. 2021.

ROCHA, João Cezar de Castro. Exercícios críticos. Chapecó: Argos, 2008. 